\title{
ChemComm
}

RSCPublishing

\section{Silver-catalysed trifluoromethylation of arenes at room temperature $\dagger$}

Cite this: Chem. Commun., 2013, 49, 6385

Received 11th March 2013,

Accepted 16th May 2013

DOI: $10.1039 / c 3 c c 41829 d$

\author{
Sangwon Seo, ${ }^{a}$ John B. Taylor ${ }^{b}$ and Michael F. Greaney*a
}

www.rsc.org/chemcomm

A variety of heteroarenes and electron rich arenes can be trifluoromethylated at room temperature with $\mathrm{TMSCF}_{3}$, catalytic silver and $\mathrm{PhI}(\mathrm{OAC})_{2}$.

The trifluoromethyl group is valued for its ability to modulate the properties of diverse materials such as pharmaceuticals, agrochemicals and polymers. Aryl $\mathrm{CF}_{3}$ groups are electronwithdrawing, hydrophobic and generally very stable, all properties that can be harnessed in the design of biologically active molecules and functional materials. Synthetic methods for aryl and heteroaryl trifluoromethylation are thus critical to the discovery and production of new molecules of high value to society. ${ }^{1}$ Recent developments in metal-mediated trifluoromethylation have produced significant advances in this area, ${ }^{2}$ with common functional groups such as aryl boronic acids and halides undergoing efficient trifluoromethylation under palladium and copper catalysis. ${ }^{3}$ Metal-catalysed trifluoromethylation of unactivated $\mathrm{C}-\mathrm{H}$ positions, by contrast, is significantly less developed and has great potential for accelerating medicinal and agrochemical syntheses. Despite some recent groundbreaking developments in this area, ${ }^{4}$ there is still great demand for the development of catalytic $\mathrm{C}-\mathrm{H}$ trifluoromethylation methods that function under mild and simple conditions.

We were interested in developing a catalytic trifluoromethylation based on silver; in contrast to its Group 11 neighbour copper there have been few reports on silver-mediated trifluoromethyla$\operatorname{tion}^{4 g, k, 5}$ and none that we are aware of using silver catalysis. The redox catalysis of silver, comprising one electron steps between 0 , $+1,+2$ and +3 oxidation states, has been scarcely exploited in synthesis relative to other late $\mathrm{TMs}^{6,7}$ and could offer productive catalytic pathways for trifluoromethylation. We have recently developed silver-catalysed decarboxylative $\mathrm{C}-\mathrm{H}$ cross-coupling under oxidative radical conditions, ${ }^{8}$ and were keen to see if a similar approach was viable for $\mathrm{C}-\mathrm{H}$ trifluoromethylation.

\footnotetext{
${ }^{a}$ School of Chemistry, University of Manchester, Oxford Rd, Manchester, M13 9PL, UK. E-mail: michael.greaney@manchester.ac.uk

${ }^{b}$ Syngenta, Jealott's Hill International Research Centre, Bracknell, RG42 6EY, UK $\dagger$ Electronic supplementary information (ESI) available: Synthesis and characterisation data for all new compounds. See DOI: 10.1039/c3cc41829d
}

We started with a screen of reaction conditions based around $\mathrm{TMSCF}_{3}$ as the trifluoromethylating agent. ${ }^{9}$ The groups of Sanford, Bräse and Wang have recently demonstrated the compatibility of this reagent with stoichiometric silver salts, ${ }^{4 g, k, 5 c}$ encouraging us that it could form the basis of a catalytic system. Using 1,4-dimethoxybenzene (1a) as the substrate, we conducted an initial solvent screen using combinations of $\mathrm{AgF}, \mathrm{TMSCF}_{3}$ and $\mathrm{PhI}(\mathrm{OAc})_{2}$ (Table 1). We worked at room temperature under air throughout, with the aim of developing a mild reaction with as broad a functional group tolerance as possible. The reaction proved sensitive to solvent choice with initially only MeCN from a selection of common organic solvents producing any reaction (entries 1 and 2). DMSO proved more effective still, affording the trifluoromethylated compound $\mathbf{2 a}$ in $51 \%$ conversion (entry 3 ). Fluoride was not a requirement, with $\mathrm{Ag}_{2} \mathrm{CO}_{3}$ being similarly effective at promoting reaction (entry 4). Alternative oxidants did not improve on $\mathrm{PhI}(\mathrm{OAc})_{2}$ (entries 5 and 6), and the use of a

Table 1 Ag-catalysed trifluoromethylation: reaction optimisation

\begin{tabular}{|c|c|c|c|c|}
\hline & 1a OMe & $\begin{array}{l}\mathrm{SCF}_{3} \text { (4 equiv) } \\
\text { idant (2 equiv) }\end{array}$ & OMe $2 a$ & \\
\hline Entry $^{a}$ & Catalyst (equiv.) & Oxidant & Solvent & Yield $^{b}(\%)$ \\
\hline 1 & $\operatorname{AgF}(1)$ & $\mathrm{PhI}(\mathrm{OAc})_{2}$ & Solvent ${ }^{c}$ & 0 \\
\hline 2 & $\operatorname{AgF}(1)$ & $\mathrm{PhI}(\mathrm{OAc})_{2}$ & MeCN & 26 \\
\hline 3 & $\operatorname{AgF}(1)$ & $\mathrm{PhI}(\mathrm{OAc})_{2}$ & DMSO & 51 \\
\hline 4 & $\mathrm{Ag}_{2} \mathrm{CO}_{3}(0.5)$ & $\mathrm{PhI}(\mathrm{OAc})_{2}$ & DMSO & 48 \\
\hline 5 & $\mathrm{AgF}(1)$ & $\operatorname{PhI}(\mathrm{TFA})_{2}$ & DMSO & 5 \\
\hline 6 & $\operatorname{AgF}(1)$ & $\mathrm{K}_{2} \mathrm{~S}_{2} \mathrm{O}_{8}$ & DMSO & 20 \\
\hline $7^{d}$ & AgF (1) & $\mathrm{PhI}(\mathrm{OAc})_{2}$ & DMSO & 35 \\
\hline $8^{e}$ & $\mathrm{AgF}(0.25)$ & $\mathrm{PhI}(\mathrm{OAc})_{2}$ & DMSO & 55 \\
\hline $9^{e_{2} f}$ & $\mathrm{AgF}(0.25)$ & $\mathrm{PhI}(\mathrm{OAc})_{2}$ & DMSO & $55\left(58^{g}\right)$ \\
\hline $10^{e, h}$ & $\mathrm{AgF}(0.25)$ & $\mathrm{PhI}(\mathrm{OAc})_{2}$ & DMSO & 60 \\
\hline
\end{tabular}

a 1,4-Dimethoxybenzene $1 \mathrm{a}(0.3 \mathrm{mmol}), \mathrm{TMSCF}_{3}(1.2 \mathrm{mmol})$, oxidant $(0.6 \mathrm{mmol}), \mathrm{F}^{-}$source or base, solvent $(1.0 \mathrm{~mL})$, room temperature, $20 \mathrm{~h} .{ }^{b}$ Yields determined by ${ }^{19} \mathrm{~F}$ NMR using 4 -fluoroanisole as the internal standard. ${ }^{c}$ THF, 1,4-dioxane, $\mathrm{MeOH},\left(\mathrm{CF}_{3}\right)_{2} \mathrm{CHOH}$, DCE, DCM. ${ }^{d}$ Under $\mathrm{N}_{2} \cdot{ }^{e}$ Slow addition of AgF to the stirring mixture of $1 \mathrm{a}, \mathrm{TMSCF}_{3}$ and $\mathrm{PhI}(\mathrm{OAc})_{2}$ in DMSO. ${ }^{f} 2$ equiv. of $\mathrm{TMSCF}_{3} \cdot{ }^{g}$ Isolated yield. ${ }^{h} \mathrm{TESCF}_{3}$ (2 equiv.) instead of $\mathrm{TMSCF}_{3}$. 
nitrogen atmosphere led to a reduction in yield (entry 7). Crucially, sub-stoichiometric amounts of silver salts proved equally effective (entries 8-10), indicating that a catalytic reaction was feasible. We settled on conditions of $\mathrm{AgF}$ ( $25 \mathrm{~mol} \%)$ with $\mathrm{TMSCF}_{3}$ (2 equiv.) and $\mathrm{PhI}(\mathrm{OAc})_{2}$ (2 equiv.), at room temperature (entry 9) to take forward. The use of the more stable (and expensive) $\mathrm{TESCF}_{3}$ reagent gave only marginal improvement (entry 10), so we continued with the cheaper $\mathrm{TMSCF}_{3}$ reagent.

Substrate scope investigations established that the procedure was effective for a variety of electron rich arenes with broad substrate scope tolerance (Table 2). For unsymmetrical substrates isomeric mixtures were generally observed, with regioselectivities consistent with radical $\mathrm{S}_{\mathrm{Ar}} \mathrm{H}$ addition (vide infra). Importantly, the reaction was compatible with halogen groups, illustrating an orthogonal reactivity to conventional C-X trifluoromethylations whereby neighbouring $\mathrm{C}-\mathrm{H}$ bonds undergo preferential reaction. The useful building blocks $2 \mathbf{f}, 2 \mathbf{g}, 2 \mathbf{h}$ and $2 \mathbf{i}$ were prepared in this fashion. Electron-withdrawing groups such

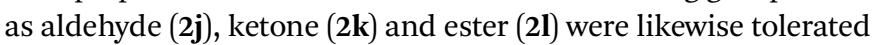
without problem. Importantly, dialkylanilines could be trifluoromethylated, a key class of building block that has rarely featured in $\mathrm{C}-\mathrm{H}$ trifluoromethylation reports. ${ }^{4 i, 10}$ A slight preference for ortho over para selectivity was observed for simple dimethylamine (2m), with bromo substitution also tolerated (2n) along with N-acylation (20). We were pleased to observe that the reaction was also effective for un-activated arenes $(\mathbf{2 p}, \mathbf{2 q}$ and $2 \mathbf{r}$ ), although these substrates did require an excess of the arene and the reaction temperature raised to $70{ }^{\circ} \mathrm{C}$.

The reaction could be extended to heteroarenes with $\mathrm{N}-\mathrm{Me}$ pyrroles in particular being excellent substrates $(2 \mathbf{s}, 2 \mathbf{t})$. Electronwithdrawing groups on the heteroarene nucleus were welltolerated (2t), but on nitrogen less so (N-Boc, 2u). Furans (2v), thiophenes $(2 \mathbf{w}, 2 \mathbf{x})$ and indoles $(2 \mathbf{y})$ were all productive, indicating that the method is viable for the major classes of $\pi$-excessive heterocycle. $\pi$-Deficient heteroarenes, by contrast, were not generally effective in the reaction but could be efficiently captured by masking the azine nucleus with electron-donating groups (2aa).

We next turned to the trifluoromethylation of more complex, biologically active molecules - a major driver for the development of new methods in this area. Introduction of the $\mathrm{CF}_{3}$ group at unactivated $\mathrm{C}-\mathrm{H}$ positions represents a very versatile approach to fluorine incorporation for modulation of biological activity, ${ }^{4 c, d, j}$ demanding mild reaction conditions that are tolerant of functional groups and reasonable stoichiometries with respect to the (often valuable) $\mathrm{C}-\mathrm{H}$ substrate. Accordingly, we extended the reaction to trifluoromethylate some more complex molecules in the agrochemistry field, an area where the $\mathrm{CF}_{3}$ group is particularly prevalent. We could successfully incorporate the $\mathrm{CF}_{3}$ group into the commercial herbicides pyriftalid ${ }^{11}$ and napropamide ${ }^{12}$ (Scheme 1). The functional group tolerance of the reaction was illustrated by sulfide, lactone and $\alpha$-hydroxyamide functionality all being stable to the reaction conditions (Scheme 1, 3 and 4 ).

A radical mechanism is implicated for the trifluoromethylation reaction, ${ }^{13}$ as radical quenching reactions using TEMPO and galvinoxyl radical both shut down the reaction, with the TEMPO$\mathrm{CF}_{3}$ adduct being clearly observed in the crude ${ }^{19} \mathrm{~F}$ NMR. The electrophilic $\mathrm{CF}_{3}$ radical usually (but with some exceptions) ${ }^{4 c, j}$
Table 2 Ag-catalysed trifluoromethylation: substrate scope $e^{a, b}$

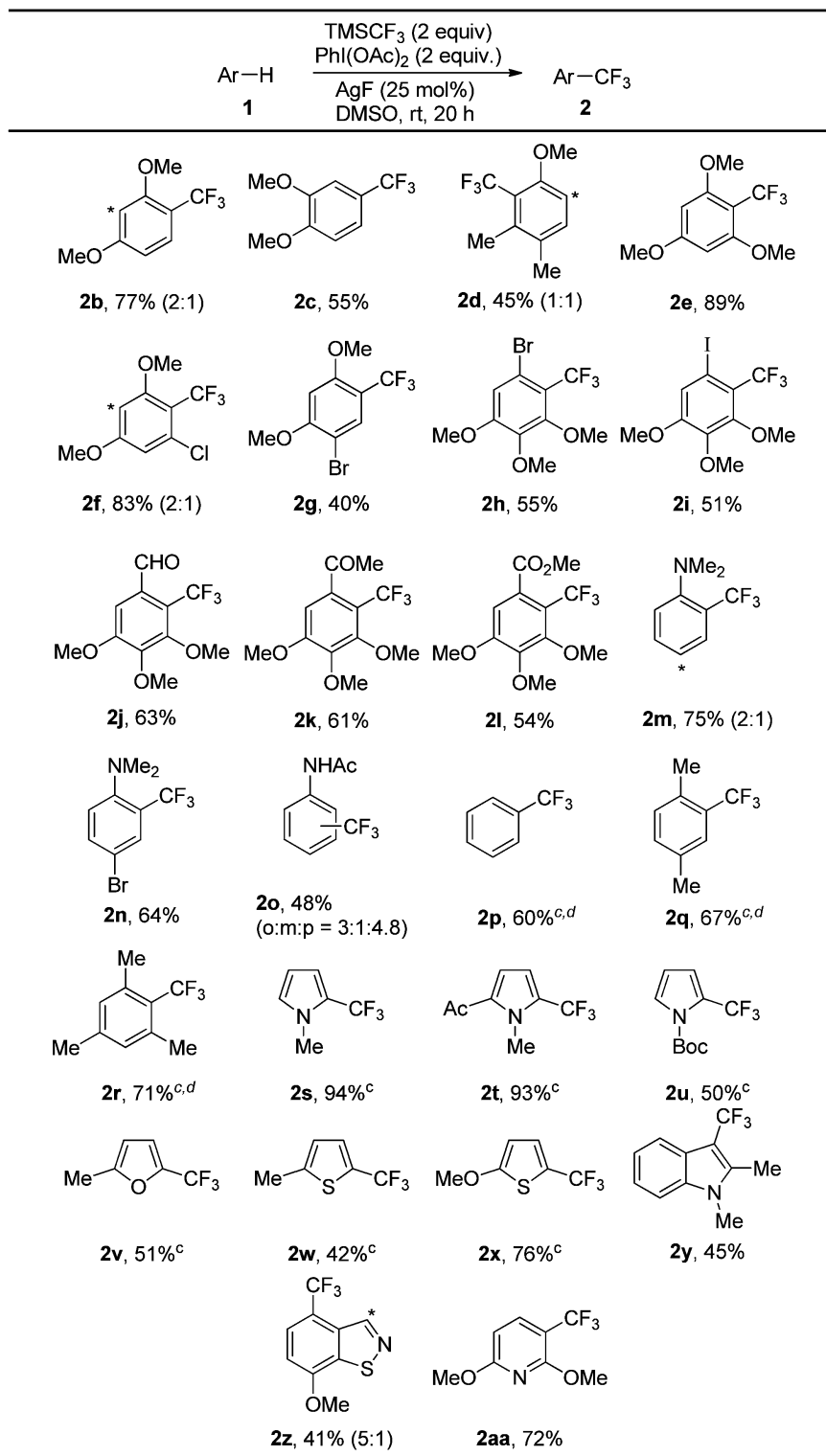

${ }^{a} 1(0.3 \mathrm{mmol}), \mathrm{TMSCF}_{3}(0.6 \mathrm{mmol}), \mathrm{PhI}(\mathrm{OAc})_{2}$ (0.6 mmol), AgF $(0.075 \mathrm{mmol})$, DMSO $(1.0 \mathrm{~mL})$, room temperature, $20 \mathrm{~h} .{ }^{b}$ Isolated yields. For isomer mixtures, the minor regioisomeric position is labeled with *. ${ }^{*}$ Yields determined by ${ }^{19} \mathrm{~F}$ NMR using 4 -fluoroanisole as the internal standard. ${ }^{d}$ Reaction conducted at $70{ }^{\circ} \mathrm{C}, 5-10$ equiv. of arene.<smiles>COc1nc(Sc2cccc3c2C(=O)OC3C)nc(OC)c1C(F)(F)F</smiles>

\section{3, $\mathrm{CF}_{3}$-Pyriftalid} $42 \%$<smiles>CCN(CC)C(=O)C(C)Oc1ccc(C(F)(F)F)c2ccccc12</smiles>

4, $\mathrm{CF}_{3}$-Napropamide
$\mathbf{5 1 \%}$
Scheme 1 Agrochemical trifluoromethylation.

displays a marked preference for electron rich substrates, as seen here, underlining the likelihood of a radical pathway. A possible 


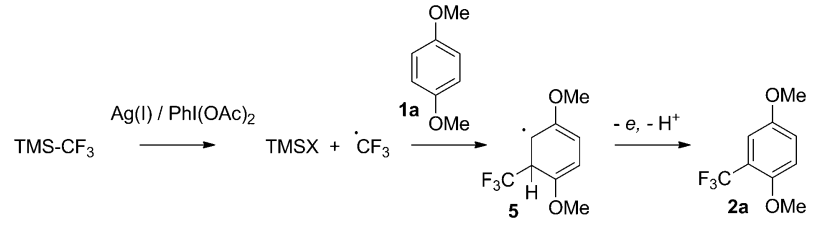

Scheme 2 Silver-catalysed radical trifluoromethylation.

mechanism is shown in Scheme 2 whereby $\mathrm{TMSCF}_{3}$ is oxidised to the $\mathrm{CF}_{3}$ radical, followed by $\mathrm{S}_{\mathrm{Ar}} \mathrm{H}$ addition, then a second one electron oxidation and proton loss to give the product 2 . Control experiments to investigate the role of silver in the first step of the proposed mechanism indicated that $\mathrm{AgF}$ alone was insufficiently oxidizing to generate $\mathrm{CF}_{3}{ }^{\bullet}$ (mixing $\mathrm{AgF}$ with $\mathrm{TMSCF}_{3}$ in the presence of TEMPO in DMSO at room temperature gave only trace quantities of TEMPO- $\left.\mathrm{CF}_{3}\right)$. $\mathrm{PhI}(\mathrm{OAc})_{2}$ alone was moderately effective (44\% NMR yield of TEMPO- $\mathrm{CF}_{3}$ ) and the combination of $\mathrm{PhI}(\mathrm{OAc})_{2}$ and $\mathrm{AgF}$ highly effective (91\% NMR yield). ${ }^{14}$ The background oxidizing activity of the hypervalent iodine reagent could be quantified in the trifluoromethylation of 1,4-dimethoxybenzene 1a in the absence of any silver salt, producing a low conversion to the trifluoromethylated product 2a (26\% NMR yield).

Alternative mechanisms were investigated by treating dimethoxyanisole 1a with in situ prepared $\mathrm{AgCF}_{3}{ }^{5 b}$ in both MeCN and DMSO as solvents. No reaction could be observed in each case, suggesting organometallic $\mathrm{AgCF}_{3}$ intermediates are not participating under our reaction conditions. A further control experiment with Togni's reagent ${ }^{4 a}$ in DMSO at room temperature gave no reaction, ruling out simple $\mathrm{S}_{\mathrm{E}} \mathrm{Ar}$ attack on an electrophilic $\mathrm{CF}_{3}$ source. Finally, we considered the possibility of initial arene oxidation by $\mathrm{PhI}(\mathrm{OAc})_{2}$, followed by $\mathrm{CF}_{3}$ anion addition to a cationic arene intermediate. Extensive work by Kita has demonstrated the $\mathrm{C}-\mathrm{H}$ functionalization of electron rich arenes using $\mathrm{PhI}(\mathrm{TFA})_{2}$ in the presence of stoichiometric $\mathrm{BF}_{3} \cdot \mathrm{OEt}_{2}$ and nucleophiles. ${ }^{15}$ It seems the present conditions are not sufficiently oxidizing to enable an analogous pathway, as a control reaction in the absence of $\mathrm{TMSCF}_{3}$ gave no reaction, where some degree of homocoupling would be expected if this mechanism was in operation.

In conclusion, we have developed a silver-catalysed trifluoromethylation system for electron rich aromatic and heteroaromatic substrates. The reaction works at room temperature under air, does not require excessive stoichiometries of substrate or reagent, and is operationally simple to carry out. The application of this chemistry to new trifluoromethylation substrates will be the subject of future work in our laboratory.

We thank Syngenta, the University of Manchester and the EPSRC for funding (Leadership Fellowship to M.F.G.), and the EPSRC mass spectrometry service at the University of Swansea.

\section{Notes and references}

1 (a) A. Studer, Angew. Chem., Int. Ed., 2012, 51, 8950; (b) O. A. Tomashenko and V. V. Grushin, Chem. Rev., 2011, 111, 4475; (c) T. Furuya, A. S. Kamlet and T. Ritter, Nature, 2011, 473, 470.

2 Recent examples of stoichiometric metal-mediated trifluoromethylation: (a) K. A. McReynolds, R. S. Lewis, L. K. G. Ackerman, G. G. Dubinina, W. W. Brennessel and D. A. Vicic, J. Fluorine Chem., 2010, 131, 1108; (b) Y. Ye, N. D. Ball, J. W. Kampf and M. S. Sanford, J. Am. Chem. Soc., 2010, 132, 14682; (c) T. D. Senecal, A. T. Parsons and
S. L. Buchwald, J. Org. Chem., 2011, 76, 1174; (d) N. D. Ball, J. B. Gary, Y. Ye and M. S. Sanford, J. Am. Chem. Soc., 2011, 133, 7577; (e) C.-P. Zhang, Z.-L. Wang, Q.-Y. Chen, C.-T. Zhang, Y.-C. Gu and J.-C. Xiao, Angew. Chem., Int. Ed., 2011, 50, 1896; $(f)$ H. Morimoto, T. Tsubogo, N. D. Litvinas and J. F. Hartwig, Angew. Chem., Int. Ed., 2011, 50, 3793; $(g)$ O. A. Tomashenko, E. C. Escudero, M. M. Belmonte and V. V. Grushin, Angew. Chem., Int. Ed., 2011, 50, 7655; (h) Y. Ye, S. A. Künzi and M. S. Sanford, Org. Lett., 2012, 14, 4979.

$3 \mathrm{Cu}$ and Pd-catalysed trifluoromethylation of functionalised arenes: (a) M. Oishi, H. Kondo and H. Amii, Chem. Commun., 2009, 1909; (b) E. J. Cho, T. D. Senecal, T. Kinzel, Y. Zhang, D. A. Watson and S. L. Buchwald, Science, 2010, 328, 1679; (c) R. Shimizu, H. Egami, T. Nagi, J. Chae, Y. Hamashima and M. Sodeoka, Tetrahedron Lett., 2010, 51, 5947; (d) T. Knauber, F. Arikan, G.-V. Roeschenthaler and L. J. Goossen, Chem.-Eur. J., 2011, 17, 2689; (e) J. Xu, D.-F. Luo, B. Xiao, Z.-J. Liu, T.-J. Gong, Y. Fu and L. Liu, Chem. Commun., 2011, 47, 4300; $(f)$ T. Liu and Q. Shen, Org. Lett., 2011, 13, 2342; $(g)$ Y. Ye and M. S. Sanford, J. Am. Chem. Soc., 2012, 134, 9034; (h) T. Schareina, X.-F. Wu, A. Zapf, A. Cotte, M. Gotta and M. Beller, Top. Catal., 2012, 55, 426.

4 Recent C-H Trifluoromethylation of arenes: (a) M. S. Wiehn, E. V. Vinogradova and A. Togni, J. Fluorine Chem., 2009, 131, 951; (b) X. Wang, L. Truesdale and J.-Q. Yu, J. Am. Chem. Soc., 2010, 132, 3648; (c) Y. Ji, T. Brueckl, R. D. Baxter, Y. Fujiwara, I. B. Seiple, S. Su, D. G. Blackmond and P. S. Baran, Proc. Natl. Acad. Sci. U. S. A., 2011, 108, 14411; (d) D. A. Nagib and D. W. C. MacMillan, Nature, 2011, 480, 224; (e) R. N. Loy and M. S. Sanford, Org. Lett., 2011, 13, 2548; $(f)$ X. Mu, S. Chen, X. Zhen and G. Liu, Chem.-Eur. J., 2011, 17, 6039; ( $g$ ) Y. Ye, S. H. Lee and M. S. Sanford, Org. Lett., 2011, 13, 5464; $(h)$ L. Chu and F.-L. Qing, J. Am. Chem. Soc., 2012, 134, 1298; ( $i$ ) E. Mejia and A. Togni, ACS Catal., 2012, 2, 521; $(j)$ Y. Fujiwara, J. A. Dixon, F. O'Hara, E. D. Funder, D. D. Dixon, R. A. Rodriguez, R. D. Baxter, B. Herlé, N. Sach, M. R. Collins, Y. Ishihara and P. S. Baran, Nature, 2012, 492, 95; $(k)$ A. Hafner and S. Bräse, Angew. Chem., Int. Ed., 2012, 51, 3713; (l) X.-G. Zhang, H.-X. Dai, M. Wasa and J.-Q. Yu, J. Am. Chem. Soc., 2012, 134, 11948; (m) X. Wu, L. Chu and F.-L. Qing, Tetrahedron Lett., 2013, 54, 249.

5 (a) W. E. Tyrra, J. Fluorine Chem., 2001, 112, 149; (b) M. M. Kremlev, A. I. Mushta, W. E. Tyrra, D. Naumann, H. T. M. Fischer and Y. L. Yagupolskii, J. Fluorine Chem., 2007, 128, 1385; (c) Z. Weng, R. Lee, W. Jia, Y. Yuan, W. Wang, X. Feng and K.-W. Huang, Organometallics, 2011, 30, 3229.

6 Silver in organic chemistry, ed. M. Harmata, Wiley, NY, 2010.

7 For silver-catalysed fluorination, see: P. Tang, T. Furuya and T. Ritter, J. Am. Chem. Soc., 2010, 132, 12150.

8 (a) S. Seo, M. Slater and M. F. Greaney, Org. Lett., 2012, 14, 2650; (b) S. Seo, J. B. Taylor and M. F. Greaney, Chem. Commun., 2012, 48, 8270.

9 G. K. S. Prakash and A. K. Yudin, Chem. Rev., 1997, 97, 757.

10 T. Akiyama, K. Kato, M. Kajitani, Y. Sakaguchi, J. Nakamura, H. Hayashi and A. Sugimori, Bull. Chem. Soc. Jpn., 1988, 61, 3531.

11 C. Luthy, H. Zondler, T. Rapold, G. Seifert, B. Urwyler, T. Heinis, H. C. Steinrucken and J. Allen, Pest Manage. Sci., 2001, 57, 205.

12 Stauffer Chemical Company, Br. Pat., GB1066606, 1967.

13 Examples of radical trifluoromethylation: (a) A. Gregorcic and M. Zupan, J. Org. Chem., 1979, 44, 4120; (b) C. Wakselman and M. Tordeux, Chem. Commun., 1987, 1701; (c) H. Sawada, M. Nakayama, M. Yoshida, T. Yoshida and N. Kamigata, J. Fluorine Chem., 1990, 46, 423; (d) B. R. Langlois, E. Laurent and N. Roidot, Tetrahedron Lett., 1991, 32, 7525; (e) K. L. Kirk, M. Nishida, S. Fujii and H. Kimoto, J. Fluorine Chem., 1992, 59, 197; $(f)$ C. Lai and T. E. Mallouk, Chem. Commun., 1993, 1359; (g) N. Kamigata, T. Ohtsuka, T. Fukushima, M. Yoshida and T. Shimizu, J. Chem. Soc., Perkin Trans. 1, 1994, 1339; (h) J.-B. Tommasino, A. Brondex, M. Médebielle, M. Thomalla, B. R. Langlois and T. Billard, Synlett, 2002, 1697; (i) T. Kino, Y. Nagase, Y. Ohtsuka, K. Yamamoto, D. Uraguchi, K. Tokuhisa and T. Yamakawa, J. Fluorine Chem., 2010, 131, 98.

$14 \mathrm{ArI}(\mathrm{OAc})_{2}$ could potentially generate $\mathrm{Ag}$ (II) as the oxidant for $\mathrm{TMSCF}_{3}$ in situ under the reaction conditions. For in situ silver(II) generation from catalytic $\operatorname{Ag}(\mathrm{I})$ and a stoichiometric oxidant in decarboxylation chemistry, see: J. M. Anderson and J. K. Kochi, J. Am. Chem. Soc., 1970, 92, 1651.

15 T. Dohi, M. Ito, N. Yamaoka, K. Morimoto, H. Fujioka and Y. Kita, Tetrahedron, 2009, 65, 10797. 